\title{
Selfies 2015: Peer teaching in medical sciences through video clips - a case study
}

J D Pillay, $\mathrm{PhD}$

Department of Basic Medical Sciences, Faculty of Health Sciences, Durban University of Technology, South Africa

Corresponding author: J D Pillay (pillayjd@dut.ac.za)

Background. Anecdotally, 2015 was declared the year of the selfie. The theme of selfies is used as an opportunity to engage neuroanatomy students by drawing from it as a newly created art form by means of models and video clips.

Objectives. To provide a synopsis of student perceptions of a team project to inform further project development and refinement.

Methods. Topics were allocated to teams of 5 - 6 students, constituting a class of 27. Teams were required to prepare a model that would demonstrate a topic, which would be used to produce a video clip presented as a teaching tool. Three focus groups comprising 6 - 8 students subsequently held discussions to determine student perspectives of the project.

Results. Students viewed the project as a means of facilitating teamwork and peer learning and of enhancing presentation skills. While all the teams enjoyed the project and found it to be beneficial, students preferred making the model rather than producing the video clip. Nonetheless, students felt particularly accomplished on seeing the completed video clip. A dominant view was that the project provided enhancement of the subject content, pertaining largely to the team's project, while the knowledge gained of other topics was limited. Some students preferred conventional teaching and found the synopsis provided by the lecturer at the end of each presentation to be particularly useful.

Conclusion. This case study provides evidence to support simple strategies of integrating discipline-specific content ('hard skills') with general education ('soft skills'), as required of higher education.

Afr J Health Professions Educ 2017;9(4):164-167. DOI:10.7196/AJHPE.2017.v9i4.803

Teaching and assessment strategies require constant personal reflection as to whether these approaches adequately prepare students to meet the discipline-specific knowledge base of the profession ('hard skills'), while simultaneously developing behavioural and attitudinal skills that empower them to become more socially aware and responsible citizens ('soft skills'). ${ }^{[1]}$ Integrating soft skills with hard skills is a conceptual principle that higher education promotes and requires, more recently popularised as 'graduate attributes. ${ }^{[2]}$ Adapting teaching and assessment practices towards addressing this need from a basic medical science and clinically applied perspective, creates the opportunity and platform to be innovative in identifying new strategies and expanding on conventional practices. Consequently, team learning has become popular in many medical training institutions. In anatomy, the limited dissection potential of the cadaveric brain, and the complexity of the three-dimensional stuctures within it, further creates a substrate for innovative learning.

This case study highlights the effectiveness of a team project that embraces the elements of hard and soft skills, team learning and self-directed learning. Topics provided required the preparation and presentation of models through a video clip as a newly created art form, so as to adopt the contemporary social theme: selfies 2015 . As it was an innovative curricular activity, it was considered giving specific attention to and evaluating the project from a student's perspective. More importantly, the project provided a simple strategy that can be used to integrate hard and soft skills, as has become a requirement of most curricula.

\section{Objectives}

A class activity has been used as a strategy to integrate hard and soft skills through the concept of a popular social theme related to the creation of an art form, and to evaluate the students' perception of the project in terms of expanding subject knowledge, personal appeal and enjoyment, and future considerations.

\section{Methods}

Each team, comprising 5 - 6 students, was allocated a topic in neuroanatomy and was required to prepare a model to demonstrate a particular aspect. Each of the three topics formed part of the neuroanatomy syllabus, but was not taught through formal lectures and practicals. For these topics, student teams were required to prepare a model relevant to the topic and produce a 15-minute video clip incorporating the model as a class presentation. Typically, each of these topics, as in previous years, would have been taught by the lecturer and, as such, contributed substantively to the subject matter. The topics, however, comprised only three of nine key topics of this section of the course and included:

- the ventricles of the brain and the flow and circulation of cerebrospinal fluid

- the arterial blood supply and venous drainage of the brain and spinal cord

- specialised grey matter within the substance of the cerebrum, with particular reference to location, structure and function.

There were no specific guidelines for the model preparation or for the presentation of the video clip. In this way, latitude was allowed among students in terms of innovation and team preferences. Students were, however, referred to the subject guide for a clear set of stipulated outcomes to be achieved for each topic in terms of the content that would need to be covered and the appropriate level of detail required. A specific time frame 
for completion of the project was also clarified. The teams were assessed equally on the model and the video clip, and a questioning session was held, where team members were questioned on relevant aspects of the topic. The allocation of marks regarding the model focused on key aspects, such as appearance and functionality, and its relationship to other relevant structures in the brain and spinal cord (where applicable). For the video clip, marks were allocated on the basis of presentation aspects, such as voice projection, clarity, engagement with and reference to the model, and pace and level of ease with which the topic content was highlighted. During the question-and-answer session marks were allocated based on how accurately students responded to questions and how well they could explain their responses, as well as the level of participation of all team members.

Students were subsequently invited to a focus group interview to document their opinions of the project. The interviews were conducted independently by an external facilitator to limit the bias of the lecturer requesting feedback from students on a teaching event facilitated by the same lecturer. Furthermore, the interviews had taken place after final course assessments were completed so that students felt comfortable during their participation or non-participation, and in providing honest feedback. As these interviews were voluntary, some students chose not to participate or were unavailable owing to the course having been completed by this time. Nevertheless, the focus group discussions were used as an opportunity to establish some awareness of student perceptions of the project and to help to engage academics in reflective practice using student feedback as a reliable source.

The questions used for the focus group discussions were based on the principle of reflective practice, which pivots on the ability and need to reflect on what, why and how we do things and to adapt and develop our practice during lifelong learning. ${ }^{[3,4]}$ This has been promoted by and required of higher education teaching. It is usually complemented by regular subject evaluations and subsequent adaptations to teaching and assessment, based on the views of students. As such, basic questions were posed to the focus groups, relating to what students enjoyed about the project, what students did not like about the project and, more importantly, how the project could be enhanced if used for future teaching, learning and assessment. Consequently, the conceptual framework of the study reporting was based on the questions used for the focus group discussions and key themes that emerged from the interviews. Focus group discussions were audio recorded and transcribed by an independent transcriptionist. Thematic analyses were used to analyse the transcripts using the NVivo Qualitative Data Analysis Software, version $10 .{ }^{[5]}$ Themes and sub-themes were created, based in part on the guided questions and data from the transcripts.

\section{Ethical approval}

Permission to obtain student feedback was obtained from the Research Ethics Committee, Durban University of Technology (ref. no. 122/15).

\section{Results}

Three focus group interviews comprising 21 of a class of 27 students ( $78 \%$ response rate), revealed the following key themes:

\section{The project}

A dominant view was that the project integrated theory and practical aspects of the topic, which was found to be enjoyable. Students appreciated working as a team, learning from each other and sharing knowledge. A further view that was often highlighted was the technical challenges faced in making the video clip. Consequently, many students preferred making the model rather than producing the video clip. There was general agreement that, despite the challenges faced during the process of completing this project, the end product and the experience gained from the endeavour were well worth the effort.

\section{Perceptions of reasons for engagement in the project}

Students viewed the project as a means of facilitating and ensuring teamwork and peer learning and as a vehicle for the enhancement of presentation skills:

'We learn it practically instead of theoretically'.

'Video method was entertaining and increased our concentration; it helped us to learn how to make a video that we can use one day when we qualify.'

'We understand better when other students teach us rather than only learning from the lecturer.'

\section{Enjoyment of the project}

While all the teams enjoyed the project, few took pleasure in making the video. It was noted that the more enjoyable part of the project was related to making the model:

'Making the model was nice and enjoyable. The video only tested our skills on how to video it. We found making the video stressful.'

Nonetheless, students found the project to be an enjoyable experience, particularly on seeing and presenting the end product (i.e. the video clip):

'We had a lovely group and we all worked well together and enjoyed working in the group. Seeing our work in the end gave us great satisfaction.'

\section{Less enjoyable aspects of the project}

Students experienced challenges in making the video and therefore found this to be a less gratifying experience than making the model. Some teams also encountered problems getting the entire group together for the video clip and experienced some technical challenges:

'We struggled with making the video, we had problems with the sound - it was "hazy". We also had problems, while presenting, with the timing (delayed) so information did not correspond with what was presented. Getting all the team members together in the limited time available was a problem, so this delayed the making of the video.'

\section{Subject content}

Collective enhancement of knowledge and its application

There was general consensus that the project provided good enhancement of the subject matter, but that this pertained largely to a particular team's project, while knowledge obtained of other topics of the section relied on the presentations and a brief synopsis by the lecturer:

'We covered the content extensively. However, the areas covered by the other teams - we had limited knowledge of these in the short presentation.'

Despite this limitation, students agreed that the exercise was fruitful in enhancing the anatomy learning experience:

'Making it, seeing the video and presenting it helps to remember better. Anatomy is good when looking at pictures - you better understand it and this helps to remember it better. Doing it yourself enhances memory because you correct it over and over again.' 


\section{The project as an alternative to conventional teaching}

While most students indicated that the experience was exciting and beneficial, some still preferred conventional teaching and found the lecturer's synopsis at the end of each presentation very useful:

'Yes, it was better, as the way it was explained was not the standard form the video was attention grasping and fun with humour, despite challenges.' 'The lecturer provided important information after the presentation. Those areas that we did not do were difficult to understand through the video clip alone, but the lecturer explained it to us after the presentation and this was beneficial.'

Some students were of the view that the experience was not beneficial:

'The making of the model and the video was a like a repetition and you stop paying attention.'

'The entire process of making the model and video - we were not learning but we were stressing about what we are presenting rather than what we are supposed to know.

There were some students who did not consider the project to be a better alternative to conventional teaching, but indicated that it can be improved on'

\section{Future recommendations}

\section{Suggested areas for improvement of this learning experience}

A dominant view that emerged from the discussions was that although this method of learning was beneficial, enhancement was needed in the form of technical assistance, especially for making the video:

'Technical assistance (a tutor) on video making must be made available to us. Also to make some kind of software available in the computer lab. This will help, as making the video can be done on the campus by all rather than at somebody's house, for example.'

Some students felt that the video clip could be replaced altogether or supplemented by a conventional power-point presentation. Students proposed that a more formative approach to the assessment should be used so that work in progress could be reviewed, with recommendations for improvement. There were also suggestions that more detailed assessment criteria should be outlined.

Some indicated that before the allocation of team projects, the lecturer should, as an example, do a similar project with the entire class, which includes dissection of an area, development of a video clip and the presentation thereof.

\section{Discussion}

In the past, most medical training institutions taught students by means of curricula that were based on the traditional model of teaching, primarily relying on the transfer of information from teacher to student. ${ }^{[6]}$ Consequently, students relied on memorisation and largely focused on shortterm recall. ${ }^{[6]}$ The transformation in higher education towards supporting more active student engagement, complemented by the changing needs and interests of students, has warranted more interactive and self-directed learning. Furthermore, there is a growing emphasis on the nature of competencies with which students leave university, which go beyond disciplinary expertise or technical knowledge, to producing generic skills, such as the ability to communicate effectively, work as a team and demonstrate responsibility. ${ }^{[7,8]}$ In this regard, the term 'graduate attributes' appears to have achieved fairly widespread acceptance in the most recent literature and is commonly used in the South African context. ${ }^{[9]}$
The focus of this study has been on transforming a conventional teaching and assessment tool (i.e. project/assignment) into an endeavour that integrates hard skills, in a self-directed and interactive manner, with soft skills, which contribute towards attaining generic capabilities emphasised in most institutional mandates emanating from the National Plan in Higher Education, 2001. ${ }^{[10]}$ More so, an attempt to incorporate the application of 'graduate attributes' in an otherwise content-based task, is inherent in this endeavour. The use of a theme relevant to current social interest provides a stimulating and contemporary appoach.

In summary, the following benefits were identified:

- The idea of the project was exciting and enjoyable.

- The project promoted and enhanced working together as a team.

- Most of the learning took place in a self-directed manner and pivoted on peer teaching and learning.

- Active engagement in the project and with the subject content promoted a deeper understanding of and more confidence in knowledge of the topic.

- The project required expansion in technical skills and abilities.

- Great satisfaction/accomplishment was felt upon completion of the project and presentation to the class.

The following key aspects were not enjoyed:

- There were technical challenges, resulting in difficulties and disappointments in terms of envisaged plans.

- The notion of a presentation and questioning session in an auditorium setting was daunting and created anxiety.

- There was limited time to work on the project as a team, which became complicated with regard to co-ordinating team meetings outside of formal contact time.

- While a high level of mastery was obtained in the topic presented by a team, there were knowledge gaps in the other two topics presented by other groups. Relying on the video clip might not have been adequate.

Suggested improvements:

- The primary recommendation was that an experienced person who could provide technical assistance for the project was needed.

- Formative feedback by a tutor or lecturer would assist in directing students during the process of the project development

- An environment more conducive to video recording would limit the need for teams to co-ordinate meeting outside the university campus.

- More clarity on the specifics of mark allocation would provide better direction and focus.

While pertinent suggestions were made for future development of the project, the task was recognised as offering an engaging, constructive and exciting space for learning beyond the limits of content-specific theory and practicals.

\section{Study limitations}

As each topic covered by the project was not covered during formal lectures, it was not possible to provide information on pre- and postintervention knowledge. For future studies it might be useful to compare student assessment performance (e.g. in a test or examination) on aspects related to these topics with other topics covered by conventional teaching within the same, if not similar, section. Nonetheless, an opportunity for reflection on student experience and insight informs future practice. 


\section{Short Research Report}

\section{Conclusion}

Allied health and medical students require active learning engagement that will allow them to move beyond the primary concern of 'content presentation and assessment' towards revisiting and improving ways of thinking and connecting information. ${ }^{[1,12]}$ The content developed in this study is recognised as being relevant, as the project involved the development of skills and processes appropriate for life beyond the context of medical science.

Acknowledgements. The author wishes to thank Miss Sara Cassim Motala for her valued input and assistance in conducting the qualitative component of the study.

Author contributions. JDP was responsible for conceptualising, conducting and reporting the study.

Funding. The study was made possible through personal research funds of the author.

Conflicts of interest. None.
South African Qualifications Authority. SAQA Bulletin 1997;1(1)

. Andrews J, Higson H. Graduate employability, soft skills versus 'hard business knowledge: A European study. High Educ Europe 2008;33(4):411-422. https://doi.org/10.1080/03797720802522627

3. Moon J. Guide for Busy Academics No. 4: Learning Through Reflection. 2005. https://nursing-midwifery.tcd. ie/assets/director-staff-edu-dev/pdf/Guide-for-Busy-Academics-Nol-4-HEA.pdf (accessed 18 September 2017). 4. Munby H, Russell T. Educating the reflective teacher: An essay review of two books by Donald Schon. J Curriculum Stud 1989;21(1):71-80. https://doi.org/10.1080/0022027890210106

5Vivo Qualitative Data Analysis Software. QSR International Pty Ltd version 10, 2012 http://www qsrinternation com/products_nvivo.aspx (accessed 18 September 2017).

6. Lachman N, Pawlina W. Integrating professionalism in early medical education: The theory and application of W. reflective practice in the nis Barrie SC. A conceptual framework for the teaching and learning of generic graduate attributes. Stud High Educ 2007;32(4):439-458. https://doi.org/10.1080/0307507070146100

8. Kember D, Leung D. The influence of active learning experiences on the development of graduate capabilities. Stud High Educ 2005;30(2):155-170. https://doi.org/10.1080/0307507050004312

9. Griessel H, Parker B. Graduate Attributes: A Baseline Study on South African Graduates from the Perspective of Employers. Pretoria: Higher Education South Africa (HESA) and the South African Qualifications Authority (SAQA), 2009.

10. Department of Education. National Plan for Higher Education in South Africa. Pretoria: DoE, 2001.

11. Gibbs G, Coffey M. The impact of training of university educators on their teaching skills, their apporach to teaching and the approach to learning of their learners. Active Learn High Educ 2004:5(1):87-100. https://do org/10.1177/1469787404040463

12. Van Amburgh JA, Devlin JW, Kirwin JL, Qualters DM. A tool for measuring active learning in the classroom. Am J Pharm Educ 2007;71(5):85-97. https://doi.org/10.5688/aj710585

Accepted 30 March 2017. 